\title{
TRADUÇÃO E INTERPRETAÇÃO DE SONHOS
}

Patricia Noronha de Sá é psicanalista, membro da Escola Letra Freudiana. E-mail: patriciasa @globo.com

\section{Resumo}

Discutiremos a interpretação de um sonho, na psicanálise, e a importância do significante na constituição da significação e dos sentidos para sua interpretação, a partir da tradução do texto do sonho.

\begin{abstract}
We intend to discuss the interpretation of a dream, in Psychoanalysis, and the relevance of the signifier to produce signification and meaning to its interpretation, from the translation of the dream.
\end{abstract}

Se traduz, o que quer dizer isso?

Jacques Lacan

Este artigo pretende discutir a questão da interpretação do sonho, em psicanálise, suscitada a partir de uma tradução, e a importância do significante na constituição da significação e dos sentidos para esta interpretação. Escolhemos para isso o relato de um sonho bastante conhecido de Anna Freud, quando ainda era pequena, suas mais relevantes interpretações e traduções. Essa questão adquiriu certo destaque por ter sido parte de uma querela teórica entre dois psicanalistas argentinos célebres, que perdurou de 1969 a 1971: Emilio Rodrigué, membro da Associación Psicoanalítica Argentina, e Oscar Masotta, responsável pela introdução e prática do ensino de Lacan em castelhano.

A querela tomou dimensões maiores quando Oscar Masotta, psicanalista de orientação lacaniana, fez uma conferência, em 1969, na qual censurava explicitamente a situação da psicanálise na Argentina que, na esteira de Lacan e seu retorno a Freud, mostrava o quanto a psicanálise freudiana estava esquecida. Referia-se para isso a Emilio Rodrigué, membro da International Psychoanalytical Association, por intermédio da Associación Psicoanalítica Argentina, e a um caso que este havia analisado, pouco tempo antes, de uma criança autista. Ao relatar o caso, Rodrigué criticava, de certa forma, o modo como Freud procedia às análises de sonho, tendo sido, justamente por isso, duramente criticado por Masotta.

Começamos por fornecer uma breve e sucinta explicação da constituição dos sonhos na psicanálise freudiana e o que estes colocam em jogo. Em seguida expomos, como eixo da discussão, a querela entre os famosos psicanalistas argentinos, Oscar Masotta e Emilio Rodrigué, ao refletir sobre a situação da psicanálise na Argentina, 
colocam em destaque os diferentes modos de interpretação de sonhos, que descrevem, por meio dos símbolos ou de significantes, tendo como pano de fundo a tradução de um sonho de Anna Freud. Optamos por apresentar nossos argumentos à medida que esses discursos fossem introduzindo novos pontos a serem considerados.

A interpretação dos sonhos, 1900, é um dos textos inaugurais de Freud e representativo de suas formulações. Lacan, entre 1953 e 1956, relê alguns sonhos nele descritos e interpretados, entre eles o sonho de Anna Freud, objeto de nossa discussão neste trabalho. Nesse livro, encontramos os elementos necessários para pensar sobre uma lógica do significante na determinação da produção de sentido e da significação, como revista por Lacan, e estabelecer um paralelo com a linguística saussuriana, as críticas feitas a esta por Jakobson e eventualmente Benveniste.

Os sonhos são formados por um conteúdo manifesto (lembranças recentes) e um conteúdo latente (lembranças infantis, material recalcado). Freud fala das possibilidades que a "língua" dos sonhos oferece para a representação ou representabilidade (Darstellung, Darstellbarkeit). Para ele, os sonhos, como eram relatados pelos pacientes, eram desprovidos de significação. No entanto, por meio de um trabalho de interpretação, de reorganização das cadeias associativas produzidas pelos pacientes era possível constituir um sentido. O inconsciente se revelou a Freud através da fala de suas pacientes histéricas, e, a partir daí, ele tentou transmiti-lo com palavras. O privilégio que dará à interpretação dos sonhos é correlativo à própria descoberta de que o inconsciente tem uma estrutura que lhe é própria.

No sonho, Freud põe em jogo três instâncias: 1) a tradução relativa à passagem de um idioma ao outro, 2) a tradução que opera o sonho (do conteúdo latente ao conteúdo manifesto), e 3) aquilo que corresponde à leitura desse texto e sua interpretação. Como a tradução que se opera no sonho do conteúdo manifesto ao conteúdo latente excede o campo da linguística, não trataremos especificamente disso, mas apenas daquilo que concerne à questão proposta neste trabalho: leitura e interpretação do texto do sonho e a correspondente passagem de um idioma a outro e sua relevância para a interpretação.

Trazemos para a discussão a importância da releitura de Lacan, ou do retorno a Freud por ele proposto, na querela mencionada, que teve início em uma conferência ${ }^{1}$ lida no Instituto Luchelli Bonadeo, em 1969, por Oscar Masotta, sobre como se encontrava a situação da psicanálise na Argentina, referindo-se a um texto de Emilio Rodrigué, criticando-o, como segue: 
A "psicanálise hoje" [...] parece estar condenada a começar pelo final. Trata-se, na essência, de transmitir uma técnica, no melhor dos casos — ou no pior - , de formalizar uma teoria sobre cujos fundamentos e alcances já ninguém se pergunta mais. Não é necessário, posto que, se ela existe na cabeça de nossos "gigantes da poltrona", é porque o Poder fundamentará o Saber [...] Porém, não faço metáforas: até tal ponto creio que o recalcado é Freud; entendo que só é possível ler alguns livros escritos por psicanalistas argentinos atentando às lacunas, olhando-os do avesso [...].

Eis aqui um retorno do discurso freudiano no discurso manifesto de um psicanalista de hoje: [...] escreve Rodrigué: considero que este mutismo é um artifício da técnica de interpretação que Freud empregava em princípios do século. O método de fragmentar os sonhos em elos arbitrários e de solicitar, às vezes pressionar o paciente para que associe com cada item, gera uma alteração da trama natural do sonho, onde os signos estão significativamente relacionados com seu texto. [...]

Vejamos o que diz o parágrafo: a) que não é possível isolar um signo de seu contexto; b) porque a significação é uma "trama natural" (esta expressão infeliz significa, sem dúvida, que temos que analisar aquilo que se tem à vista, a imagem do sonho, por exemplo, e não as palavras) $)^{2}$; c) que a significação só é legível no interior do contexto atual e global do signo ou símbolo. Mas, não se reconhecem as teses de uma fenomenologia da totalidade (aliada à locação sempre pragmatista dos textos do autor; mas isto não é menos significativo) que enfatiza o molar devido a um cego desprezo pelo fragmentário, pelo "molecular", pelas "partes"? Inquietude, enfim, já suficientemente derrocada pela linguística contemporânea. Como poderia haver significação - e isso tanto fora como dentro da psicanálise - se o signo não levasse em si mesmo seu próprio princípio de fragmentação, de isolamento do texto e de todo contexto (sua inerência ao código e seu potencial poético) e seu próprio princípio de cisão interna (a barra saussuriana, que separa o significante do significado, não é nem um descobrimento do linguista, nem um privilégio do esquizofrênico). Como poderia haver inerência do "item" ao seu contexto, sem significante, isto é, sem essa materialidade de exterioridade absoluta e a priori, que define a materialidade da linguagem; enfim, sem a possibilidade de qualquer palavra (monema ou frase) de ser tomada à letra, como diz Lacan, tomada letra por letra ou decomposta, no extremo, em suas letras, facilmente convertível em seu anagrama, e sem que esses produtos moleculares da desconstrução não fossem capazes de novas travas e de formar elos e cadeias (por suas semelhanças, formais, sonoras; por suas diferenças) e de abrir e fechar ao mesmo tempo o trânsito do sentido e da significação? Que assevera Rodrigué? Antes de mais nada, uma amputação da teoria freudiana do significante: esta ficará reduzida aos problemas do simbolismo. (Masotta, 1969, p. 20-21, tradução e grifo nosso).

A propósito dessa referência a Rodrigué e sua interpretação de sonhos, Oscar Masotta faz a seguinte análise do sonho da pequena Anna Freud:

Em Freud, as coisas ocorriam de outro modo, eram menos seguras, mais sérias, menos simples. Rodrigué reconhece uma diferença entre necessidade e. . . outra coisa; em Freud essa outra coisa tinha um nome preciso: desejo; e se o sonho deveria ser 
considerado como Via Real, era porque conduzia ao desejo subjacente, e este, sempre esquivo, sempre necessário de fixar ou de definir - porém jamais ausente - ensinava que o ego era uma ilusão e definia o sujeito por sua posição (por sua localização, teríamos que dizer) em um discurso tanto mais verdadeiro quanto mais enganoso e enganador; o inconsciente. Resulta claro e óbvio que não se pode reduzir o sonho da pequena Anna Freud ao exemplo de Ferenczi do ganso que sonha com o milho ou do porco que sonha com a ração; impossível ao menos, deixar de lado esta diferença: o sonho da pequena Anna se articula em voz alta durante o dormir. "Ana F(r)eud, $f(r)$ esas, $f(r)$ ambuesas, bollos, papilla". No caso do animal - e se é que este, propriamente falando, sonha - existe uma "unidade eletiva da satisfação da necessidade. Enquanto no sonho de Anna - e é isso o que lhe outorgará um valor exemplar aos olhos de Freud - o significante encontra-se presente". De que maneira? $\mathrm{Na}$ repetição de um grupo fônico, na escansão que a repetição introduz, no efeito, enfim, de ordenamento retórico e de hierarquização interna e autônoma das palavras e das frases, na atomização do significado da frase e na restituição do sentido introduzido pela mesma repetição (o "denominador comum" diz Lacan indicando a importância dos parênteses). (Masotta, 1969, p. 21, grifo nosso)

\section{$[\ldots]$}

A diferença entre o exemplo de Freud e o de Rodrigué reside em que a pequena Anna produz, com as palavras existentes no código da língua, as paronomásias e distribuições pelas quais o desejo aparece articulado ("realizado" em e unicamente por essa articulação linguística). (Masotta, 1969, p. 22, tradução nossa.)

Rodrigué responde com um texto intitulado "Leer a Rodriguê" no qual critica a interpretação de Oscar Masotta perguntando-se: "Como está presente - segundo Masotta - o significante neste sonho?” (Rodrigué, 1969, p. 127, grifo e tradução nossa).

Ana é Anna Freud, filha de Freud. Masotta informa-nos que o sonho da 'pequena Anna articula-se em voz alta durante o sono: Ana F(r)eud, $f(r)$ esas, $f(r)$ ambuesas, bollos, papilla'. Cito-o novamente: $\mathrm{Na}$ repetição de um grupo fônico, na escansão que a repetição introduz, no efeito de ordenamento retórico e na hierarquização interna e autônoma das frases... "Para Masotta, os 'fr' em Freud, frambuesas e fresas são importantes. Mas a questão é: para quem? Seguramente não para a pequena Anna. Ela era austríaca e as crianças austríacas sonham em alemão. Gol de meio do campo! [...] O problema é que não sei bem se compreendo, além disso, a palavra 'paronomásia' me surpreende. No dicionário soube que quer dizer a semelhança entre duas vogais acentuadas. (Rodrigué, 1969, p. 127, tradução nossa.)

Gostaria de apresentar, então, para abrirmos nossa discussão, as traduções, desse sonho da pequena Anna Freud mais conhecidas entre nós: James Stratchey traduziu 
para o inglês, Luis López-Ballesteros para o espanhol e Jayme Salomão esteve na direção geral e revisão técnica para o português, a partir do inglês como língua-fonte, para a Editora Imago; e, finalmente, o original em alemão:

My youngest daughter, then nineteen months old, had had an attack of vomiting one morning and had consequently been kept without food all day. During the night after this day of starvation she was heard calling out excitedly in her sleep: "Anna Fweud, stwawbewwies, wild stwawbewwies, omblet, pudden!" At that time she was in the habit of using her own name to express the idea of taking possession of something. The menu included pretty well everything that must have seemed to her to make a desirable meal. (Freud, 1998, p. 163)

Teniendo mi hija menor diecinueve meses, hubo que someterla a dieta durante todo un día, pues había vomitado repetidamente por la mañana. A la noche se le oyó exclamar enérgicamente en sueños: "Ana $F(r)$ eud, $f(r)$ esas, $f(r)$ ambuesas, bollos, papilla." La pequeña utilizaba su nombre para expresar posesión, y el menú que a continuación detalla contiene todo lo que podía parecerle una comida deseable. (Freud, 1968, p. 322)

Minha filha mais nova, então com dezenove meses de idade, tivera um ataque de vômitos numa certa manhã e, em consequência, ficara sem alimento o dia inteiro. Durante a noite, nesse dia de fome, ouvia-se que ela gritava excitadamente enquanto dormia: "Anna Fwend, mo-rranga, mo-rranga silvestras, ombleta, podim!" Naquela época, Anna tinha o hábito de usar seu próprio nome para expressar a ideia de se apossar de algo. O menu incluía perfeitamente tudo o que lhe devia parecer constituir uma refeição desejável. $\mathrm{O}$ fato de os morangos aparecerem nele em duas variedades era uma manifestação contra os regulamentos domésticos de saúde. Baseava-se no fato, que ela sem dúvida havia observado, de sua ama ter atribuído sua indisposição a uma indigestão de morangos. Assim, ela retaliou no sonho contra esse veredicto indesejável. (Freud, 1969, p. 139)

Mein jungstes Mädchen, damals neunzehn Monate alt, hatte, eines Morgens erbrochen und war darum den Tag über nuchtern erhalten worden. In der Nacht, die diesem Hungertag folgte, hörte man sie erregt aus dem Schlaf rufen: Anna F. eud, Er(d)beer, Hochbeer, Eier(s)peis, Papp. Ihren Namen gebrauchte sie damals, um dip Besitzergreifung auszudrucken; der Speisezettel umfaßte wohl alles, was ihr als begehrenswerte Mahlzeit erscheinen mußte. (Freud, 1972, p. 134)

Observamos que as traduções do original em alemão procuram expressar, da melhor forma possível, em cada língua-alvo, a fala da pequena Anna. Como nos diz Freud, ela tinha apenas 19 meses de idade e falava como criança, tendo cometido alguns erros ao subtrair determinadas letras em alemão, deixando inclusive de pronunciar o " $\mathrm{r}$ " do próprio nome, assim como as outras palavras em alemão que, se estivessem corretas, seriam: Anna Freud, Er(d)beere, Hochbeer, Eier(s)peise, Papp. 
Algum tempo depois, Oscar Masotta escreve uma resposta a Rodrigué e desta interessa-nos destacar o que diz acerca das traduções: "Nem López-Ballesteros nem Stratchey leram mal Freud [...] Os psicanalistas podem escamotear o significante mas os tradutores não.” (Masotta, 1971, p. 61, tradução nossa). Luis López-Ballesteros foi o tradutor das obras de Freud para o espanhol e James Stratchey, para o inglês, como dissemos anteriormente.

Perguntamo-nos então: que linguística e que teoria da tradução convêm àquilo que Freud descreve no fenômeno do sonho? Essa tradução para o espanhol e a interpretação que suscita estariam operando com uma linguística em torno do signo? ou do sentido? ou da significação? O sonho expõe outra maneira de colocar a linguagem: o significante! Como diz o próprio Freud: "Excedo, sem dúvida o significado usual da palavra ao postular o interesse da psicanálise para o investigador da língua." (1972, p. 389).

Os sonhos encontram-se, segundo Freud, ligados à expressão verbal. Ferenczi, por exemplo, observava que cada língua teria seu próprio idioma onírico. Um sonho seria, portanto, "intraduzível", de certa forma, para outros idiomas.

A tradução em psicanálise não é redutível ao passo de sentido, ${ }^{3}$ de um idioma para o outro, de uma margem para a outra. Freud enfatiza na citação a seguir que o valor simbólico dos sonhos, mesmo apresentados como imagens, não pode ser interpretado apenas como composição pictórica. Ele coloca a palavra em jogo em inúmeras possibilidades combinatórias que nomeia: palavras combinadas, compostas, jogos de palavras, palavras ponte. (Koop, 1988).

Como se lê um sonho? O significante psicanalítico supõe uma letra que estabelece relações muito distintas do que se suporia, por exemplo, a uma simples representação fônica. Lacan enuncia: a letra, isso se lê! Que espécie de leitura a letra põe em jogo? Como se lê esta letra? A terminologia que se constrói para dar conta do fenômeno do sonho é eminentemente figurativa, representacional, de imagens. O sonho parece ocorrer em "outra cena", diante dos olhos. Assim, ouvimos frases como "tenho diante de mim", "me vejo em tal lugar". Um dos mecanismos que permitem a construção de um sonho é o cuidado com a representabilidade (Darstellbarkeit), algo muito próximo à encenação.

Os pensamentos oníricos são, sem mais, compreensíveis assim que tomamos conhecimento deles. O conteúdo do sonho é dado, por assim dizer, numa escrita pictográfica cujos signos devem ser transferidos, um a um, para a linguagem dos pensamentos dos sonhos. Se tentássemos ler esses signos segundo seu valor pictórico, e não de acordo com seu valor significante, seríamos claramente induzidos ao erro. 
Suponhamos que eu tenha diante de mim um enigma feito de figuras (um rébus): uma casa, em cujo telhado se pode ver um barco, uma única letra, em seguida a figura de uma pessoa correndo, cuja cabeça sumiu, e assim por diante. Eu poderia incorrer na crítica de declarar sem sentido essa composição e suas partes constitutivas. Um barco não pertence ao teto de uma casa e um homem sem cabeça não pode correr; além disso, a pessoa é maior do que a casa e, se o todo inteiro deve representar uma paisagem, as letras separadamente não se encaixam ali, pois não existem na natureza livre. O juízo correto do rébus só se dá com clareza quando eu, em vez de fazer tais objeções contra o todo e as partes, esforço-me, porém, para substituir cada figura por uma sílaba ou palavra que seja representável segundo alguma relação. As palavras assim compostas não são mais sem sentido, mas podem produzir os mais belos e significativos ditos poéticos. O sonho é um enigma desse tipo, e nossos antecessores no campo da interpretação dos sonhos cometeram o erro de julgar o rébus como uma composição de desenhos. E como tal ela lhes pareceu sem sentido e sem valor. (Freud, 1972, p. 280)

Em A interpretação dos sonhos, Freud, 1900, orienta o trabalho de modo que cada fragmento seja tratado em detalhe, mas sem perder de vista o todo, o modo pelo qual essas partes se articulam na produção do sentido final do sonho (a posteriori). A cena inconsciente desvela esses fragmentos, mas na forma do não-senso. O sentido só é produzido pelo encadeamento dessas unidades fragmentárias, os intervalos existentes também são essenciais ao trabalho da interpretação, pois neles encontram-se impressos os efeitos da elaboração onírica que estão a serviço da censura, que realizam os disfarces necessários para que o pensamento latente possa se revelar através do manifesto. A interpretação, portanto, faz o caminho contrário ao da formação do sonho. Por essa razão o caráter fragmentário da interpretação nos sonhos é importante, afinal, ele faz parte da própria lógica interpretativa. Isso indica que uma interpretação é sempre inacabada, que ela não é uma tarefa de totalização, pois além de não ser possível recobrar um sentido originário para as formações do inconsciente, cada fragmento permite infinitas interpretações pelo aspecto da sobredeterminação. Freud é enfático em salientar que sua técnica interpretativa depende não só do relato do analisante, mas sobretudo das associações que este é capaz de realizar, ressaltando com isso que cada tratamento é único. O que realmente importa na técnica proposta por Freud é o movimento associativo do sujeito em análise.

A ambiguidade dos diversos elementos dos sonhos encontra paralelo nos antigos sistemas de escrita. "A linguagem dos sonhos pode ser encarada como o método pelo qual a atividade mental inconsciente se expressa" e o "inconsciente fala mais de um dialeto". (Freud, 1969, p. 212)

Vemos como a linguagem está profundamente implicada na psicanálise e no inconsciente. As formações do inconsciente são, principalmente, aquilo que rateia na 
fala e na escrita. Freud, ao estudar os fenômenos de "lapso de língua", "lapso de escrita", "lapso de leitura" e muitos outros, buscou os trabalhos de filólogos como Abel, Sperber entre alguns outros, procurando antes pelo que já havia sido discutido nessa área específica.

Para Lacan, como para Freud antes dele, não é tal ou tal forma de linguística que importa - a estruturalista mais que a transformacionista, a sincrônica, mais que a diacrônica - mas um único fato de que, tocando a língua alguma coisa da ordem de uma escrita seja possível: para Freud bastava a gramática comparada e um pouco incerta de Abel, foi suficiente. Lacan tem mais exigências, mas no fundo são poucas: não lhe é nem mesmo necessário que a linguística, se ela exista para sua própria satisfação, seja clara sobre seus próprios métodos. (Milner, 1987, p. 42)

Lacan, em 1953, quando propõe seu retorno a Freud no famoso Discurso de Roma, ou Função e campo da palavra e da linguagem, procura exatamente recuperar a letra de Freud que estaria perdida nos desdobramentos da psicanálise nos anos seguintes à sua morte: a psicologia do ego, formulações e prolongamentos que estariam, segundo ele, cada vez mais distantes da psicanálise de Freud. Como aponta, no caso, Masotta em seu discurso sobre o estado da psicanálise na Argentina.

Nesse escopo está também a interpretação dos sonhos e nosso sonho de Anna Freud, a interpretação que recebeu nesse ínterim e que procurava encontrar o sentido e o simbolismo do sonho, como fazia Ernest Jones, por exemplo.

Na teoria do simbolismo de Jones, em 1926, o símbolo se deslocaria de uma ideia mais concreta para uma ideia mais abstrata, com a qual se relacionaria de maneira secundária, indicando, desse modo, que o deslocamento só poderia acontecer em um sentido único, de modo que o símbolo passa, em geral, de uma ideia mais importante para uma menos essencial. Entretanto, ele reconhece que o simbolismo analítico só é concebível se estiver relacionado com a metáfora. Trata o sonho como uma totalidade, e o interpretante esforça-se por substituir por outro conteúdo, análogo porém mais inteligível. Para Freud esse método seria aquele que poderia ser utilizado em "sonhos artificiais", como os inventados por escritores e poetas. O método empregado por ele seria o do deciframento: o sonho é tomado como texto codificado, ou cifrado, como pudemos constatar em suas próprias palavras, quando esclarece na citação feita neste texto, o que seria um pensamento onírico, e que cada elemento pode ser traduzido. Esse método não considera o sonho como uma totalidade mas como um conjunto de elementos a serem abordados separadamente.

Podemos observar isso também na crítica feita a Freud, por Rodrigué, referindose ao que ele teria denominado mutismo. Freud afirmou que "os sonhos se valem dos 
símbolos para a representação disfarçada de seus pensamentos latentes" (Freud, 1972, p. 375). Não significa que os sonhos tenham um simbolismo particular, mas que se utilizam das simbolizações já constituídas no pensamento inconsciente, pois assim podem escapar da censura. A essas simbolizações ele se refere, em A interpretação dos sonhos, como "elementos mudos", (Freud, 1972, p. 384). O indivíduo seria incapaz de fornecer associações sobre esses símbolos; apenas a técnica que se baseia nas associações do sonhador pode preencher as lacunas provenientes do conhecimento dos símbolos pelo intérprete.

Assim, inspirado nos textos lacanianos e nas reformulações que promoviam seu retorno a Freud, Masotta, em 1969, interpreta o sonho de Anna Freud com base no texto em espanhol. Rodrigué, ainda em 1969, por sua vez, para quem o significante e sua materialidade não faziam o menor sentido, achou ter conseguido fazer uma crítica brilhante à análise de Masotta "informando-lhe" que Anna Freud "era austríaca" e sonhava em "alemão"! Chegou a acreditar ter feito um "gol de meio de campo" com esse comentário. Embora tenha estranhado que nenhum psicanalista de orientação lacaniana tenha protestado, considerou sua argumentação perfeita.

Vejamos, então, como a psicanálise lacaniana e, sobretudo, a releitura que Lacan faz de Saussure realiza operações que, além de permitirem, possibilitam não só a tradução como a interpretação adequada do sonho.

Lacan apropriou-se da linguística saussuriana e dos conceitos e críticas de outros linguistas como Benveniste e Jakobson. Ele, no início de seu texto Instância da letra no inconsciente, afirma: "é toda a estrutura da linguagem que a experiência psicanalítica descobre no inconsciente." (Lacan, 1998, p. 498). Com relação a Saussure, toma-o principalmente em dois pontos importantes. Primeiro quando utiliza a linguagem como condição de possibilidade para a psicanálise: "a realidade humana é irredutivelmente estruturada como significante" (Lacan, 1985, p. 227). E, segundo, quando toma a teoria do signo de Saussure, reformula-a, reelaborando a partir daí um conjunto de questões como o conceito de signo, significante, significado, sujeito, língua, linguagem, etc.

Uma das modificações que Lacan promove é a inversão, no signo, do significante e do significado. O significante passa ao lugar do termo superior e o significado ao do termo inferior. Isso porque, para ele, o significado não tem predomínio sobre o significante e ambos não possuem o vínculo descrito por Saussure. Lacan não se interessa em discutir se a relação entre o significante e o significado é arbitrária ou necessária. O que interessa a Lacan é romper com a 'visão representativa do significante'. A linguagem nos interroga do lugar em que o sistema significante somente por meio de relações diferenciais é capaz de produzir efeitos de significado. A 
noção da relação significante/significado como sendo arbitrária surge, para Saussure, talvez para dar conta da origem do signo.

Em seguida, ele rompe com a unidade estrutural do signo assim como com as partes que o constituem, suas propriedades e seus princípios. Para Saussure, o significante remeteria necessariamente a um significado e se estabeleceria entre eles uma relação biunívoca entre os sons (imagens acústicas) e os pensamentos (ideias), respectivamente. A função do significante seria apenas a de representar o significado. Ao procurar uma imagem que representasse o "fato linguístico em seu conjunto, isto é, a língua," (Saussurre, 1987, p. 130-131) Saussure utiliza uma figura na qual vemos o plano indefinido das ideias confusas sobre o plano não menos indeterminado dos sons. Para Lacan, "F. de Saussure ilustra com uma imagem que se assemelha às duas sinuosidades das Águas superiores e inferiores nas miniaturas dos manuscritos do Gênesis". Com isso, ele faz uma alusão à separação das águas no livro do Gênesis, a dois planos sobrepostos, tal qual as águas com o firmamento entre elas, o "plano indefinido das ideias confusas", e o "plano indeterminado dos sons" descritos por Saussure, cuja interseção é a língua. Lacan, então, promove outras alterações radicais. Ele postula uma estrutura significante autônoma e determinante em relação aos efeitos de significação, e desloca para as leis de relação entre os significantes, metáfora e metonímia, a responsabilidade pela atualização da significação. Rompe desse modo com a relação existente entre significante e significado que estarão agora "separados inicialmente por uma barreira resistente à significação" (Lacan, 1998, p. 500). Com essa ruptura, ele elimina a elipse dentro da qual se encontrava o signo saussuriano que indicava, justamente, a indissociabilidade entre significante e significado. Tanto que, para Saussure, o signo linguístico seria uma entidade psíquica de duas faces, unindo de forma biunívoca os reinos do pensamento e dos sons. Lacan liberta o significante de sua função de representar o significado, pois acredita que esse vínculo conduz a uma lógica positivista à busca de sentido do sentido. O significante só produzirá significação por retroação (a posteriori) de remetimento de um significante a outro.

O signo, cuja arbitrariedade foi também criticada por Benveniste e Jakobson, manteve alguma determinação do objeto na produção de significação. Essa é a crítica de Lacan quando diz que fracassaremos enquanto não nos libertarmos da ilusão de que o significante responde à função de representar o significado. É preciso romper com essa noção de representatividade da linguagem e partir para um significante desprovido de qualquer significação. A linguagem nos interroga desse lugar de sistema significante que apenas por relações diferenciais pode produzir efeitos de significado.

O linguista postula a ligação arbitrária entre palavra e coisa para responder a uma questão sobre a origem da linguagem, como se buscasse a origem da linguagem 
fora dela própria. É preciso pensar, para Lacan, pelo menos no início, a linguagem como um sistema autorreferencial, que se determina, como o Real.

$\mathrm{O}$ arbitrário, o acaso, na teoria lacaniana, está submetido à lei do a posteriori nachträglich - do sentido. O significante constitui uma cadeia, simbólica, que lhe préexiste, submete e determina.

A linearidade do signo linguístico é a linearidade do significante como Lacan mesmo escreve:

Mas a linearidade que F. de Saussure considera como constituinte da cadeia do discurso, conformemente a sua emissão por uma única voz e na horizontal, onde se inscreve em nossa escrita, se ela é necessária, com efeito, não é suficiente. Ela se impõe à cadeia do discurso apenas na direção em que é orientada no tempo, sendo mesmo aí ornada como fator significante em todas as línguas em que: [Pedro agride Paulo] reverte seu tempo ao inverter seus termos. (1998, p. 506)

A linearidade é necessária mas não suficiente, pois, embora o discurso seja organizado em uma linha sucessiva no tempo, ele não é constituído por uma única cadeia de elementos significantes mas por várias cadeias, produzindo um efeito do que Lacan chama de polifonia, superpondo o conceito freudiano de sobredeterminação e o de Jakobson de feixe de traços distintos da linearidade.

O desenvolvimento teórico de Lacan vai em direção a um esvaziamento do conceito de signo já que separa significante de significado. Retomando: como se produz, então, a significação na teoria lacaniana? Por uma estrutura articulada regida por leis que singularizam suas unidades: segundo as leis da metáfora e da metonímia.

O que Freud designa como condensação seria a estrutura de superposição dos significantes, o que se chama em retórica metáfora. E o deslocamento, o transporte da significação, constitui a metonímia. O trabalho do sonho segue, portanto, as leis do significante. $\mathrm{O}$ significado desaparecido, pelo recalque, se exprime pelo significante.

“As imagens do sonho só devem ser retidas por seu valor significante. [...] Essa estrutura de linguagem que possibilita a operação de leitura está no princípio da significância do sonho" (Lacan, 1998, p. 514).

Os significantes seriam os elementos separados, privados de sentido. Eles são em si mesmos sem sentido e podem vir a significar qualquer coisa. A questão da significação envolve além da metáfora e da metonímia outro conceito psicanalítico elaborado por Lacan: Outro.

O imaginário seria o que amarraria o significante a uma relação biunívoca com o significado. Os significantes, entretanto, podem se combinar para formar sentidos inusitados. A relação entre os significantes de uma cadeia repete no campo do simbólico 
a relação da falta e de impossibilidade que caracteriza o Real. Por ser sem sentido, o significante só encontra sentido em outro significante. Podemos assim entender a necessidade deste remetimento na relação a posteriori.

Quando Lacan fala do significante, retira todo o seu matiz visual, representacional. A imagem passa a ter uma interpretação pelo significante. Freud/Lacan aproximam esse significante ao ideograma, ao hieróglifo. Nesse sentido, a letra se lê a partir de um significante. Justamente por possuir características de uma escrita desconhecida por quem lê. Como alguém que está começando a ser alfabetizado.

Percebe-se bem o distanciamento entre o representacional, a imagem e o significante no texto de Lacan À memória de Ernest Jones, 1959, no qual ele critica o trabalho de Jones sobre o simbolismo, que mencionamos anteriormente. Nesse escrito podemos ler uma teoria da letra na perspectiva do significante.

Apesar de Lacan indicar que a substituição metafórica só é possível em consequência da concatenação significante, ele mantém sua concepção de metáfora, no entanto, apoiada nas formulações de Jakobson. A substituição de um significante por outro só pode ocorrer em função de uma similaridade posicional, ou seja, em função do lugar que o significante ocupa em uma cadeia, e não de sua semelhança com o significado.

Vejamos, agora, a vertente metonímica do sentido.

Se uma parte tardia da investigação analítica, aquela que concerne à identificação e ao simbolismo, está do lado da metáfora, não negligenciemos o outro lado, aquele da articulação e da contiguidade, com o que aí se esboça de inicial e de estruturante na noção de causalidade. A forma retórica que se opõe à metáfora tem um nome - ela se chama metonímia. Ela concerne à substituição de alguma coisa que se trata de nomear - estamos, com efeito, no nível do nome. Nomeia-se uma coisa por uma outra que lhe é o continente, ou a parte, ou o que está em conexão com. (Lacan, 1985, p. 250)

A função primordial de tudo que se torna nome é de perder a referência ao objeto. A metonímia define-se, pois, como a função significante por excelência, na medida em que a operação que faz desaparecer a coisa, quando a nomeamos, é a mesma que encontramos nesse tipo de conexão em que a substituição de um significante por outro acarreta o desaparecimento maciço do primeiro - índice primário da falta do objeto do desejo.

Enquanto o processo de conexão metonímica é implícito, posto que um significante desaparece, na metáfora, ao contrário, ele é explícito, pois o significante recalcado mantém algum tipo de relação com seu substituto.

Cabe destacar que os dois processos sempre ocorrem juntos: 
A centelha criadora da metáfora não jorra da apresentação de duas imagens, isto é, de dois significantes igualmente atualizados. Ela jorra entre dois significantes dos quais um substitui o outro tomando-lhe o lugar na cadeia significante, o significante oculto permanecendo presente pela sua conexão (metonímica) com o resto da cadeia (Lacan, 1998, p. 510).

Como para Lacan o sentido, em termos estritamente linguísticos, parte desses dois casos em que a ênfase do processo de significação é colocada na mensagem, o sentido, então, só se produz "a posteriori", a partir dos cortes estabelecidos no discurso que remetem, retroativamente, cada termo da frase sobre o anterior. Haveria, portanto, um privilégio das relações de concatenação dos significantes, da função poética da linguagem (através das leis da metáfora e da metonímia), ou seja, da sintaxe em relação à semântica. Esse privilégio decorre das próprias exigências teórico-práticas da psicanálise: a linguagem, agora, só pode ser concebida na sua realização discursiva (na fala) enquanto um sujeito está aí implicado.

É justamente a introdução do sujeito na estrutura da linguagem que marcará a distinção radical da psicanálise lacaniana em relação à linguística estrutural. Em virtude dessa "intromissão" temos, pelo menos, duas consequências: a cisão do sujeito, causada pelo significante, e uma espécie de furo na estrutura da linguagem, causado por sua impossibilidade de significar o sujeito. Essas formulações reequacionam a questão do sentido, que acaba perdendo o privilégio que tinha na teoria linguística. A cisão do sujeito, o inconsciente, introduz a dimensão do não-senso como ponto de partida e ponto de retorno de toda a questão do sentido.

Depois de discutirmos a questão da linguagem na teoria lacaniana gostaríamos de retomar a questão dos sonhos. Para Freud todo sonho é a realização de um desejo. É verdade que o caráter elementar do sonho infantil parece afastar-se de suas exigências. Vimos o princípio: “o sonho traz a realização direta, não disfarçada 'de um' desejo" (Freud, 1969, p. 683).

É a reação a um acontecimento do dia que deixou um pesar (Bedauern), um desejo (Sehnsucht), uma promessa não cumprida. Isso também acontece nos sonhos de adultos, mas estes se servem dos "restos diurnos" para desencadear o trabalho complexo do recalcado. Na criança, a proximidade com o acontecimento do dia mostra a importância do que é vivido no pré-consciente. (Assoun, 2008, p. 13-24)

Anna Freud está adormecida - as coisas estão, vocês estão vendo, em estado puro fala em seu sonho: Morangos grandões, framboesas, flans, mingaus.

Eis algo que parece ser do significado em estado puro. E é a forma mais esquemática, mais fundamental, da metonímia. Sem dúvida alguma ela os deseja, aqueles morangos, 
aquelas framboesas. Mas não é evidente que esses objetos estejam ali todos juntos. Que estejam ali, justapostos, coordenados na nominação articulada, se deve à função posicional que os coloca em posição de equivalência. [...]

A frase começa pelo nome da pessoa, Anna Freud. É uma criança de dezoito meses e estamos no plano de nomeação, da equivalência, da coordenação nominal, da articulação significante como tal. É somente no interior desse quadro que é possível a transferência de significação.

É o cerne do pensamento freudiano. A obra começa pelo sonho, seus mecanismos de condensação e de deslocamentos, de figuração, todos eles são da ordem da articulação metonímica, e é sobre esse fundamento que a metáfora pode intervir. [...]

Não se pega a linguagem por uma extremidade, como certos pintores começam seus quadros pelo lado esquerdo. A linguagem, para nascer, deve sempre ser tomada em seu conjunto. Em contrapartida, para que possa ser tomada em seu conjunto, é preciso que ela comece a ser tomada pela ponta do significante. (Lacan, 1985, p. 259-260)

“Anna, grosses fraises, framboises, flans, bouillies" (Lacan, 1981, p. 258). A menina deseja as guloseimas que lhe são proibidas; estas se colocam, pois, como equivalentes do ponto de vista de sua função posicional. [...] os dois são tomados como equivalentes no que se refere à sua função posicional. É por poder ocupar a mesma posição, que esses significantes podem, consequentemente, se identificar, produzindo um efeito de sentido (metáfora).

É fácil agora entender por que nenhum psicanalista lacaniano saiu em defesa de Masotta. Retomemos a partir da interpretação de Lacan o que disse Masotta sobre o sonho, ainda que o tenha lido em espanhol na tradução de López-Ballesteros. Sua interpretação estava em consonância com as teorias psicanalíticas freudiana e lacaniana. Na primeira crítica a Rodrigué ele indica, com razão, que é possível isolar um signo de seu contexto; afinal, para que o sonho cumpra sua missão, ele passa por processos de condensação e deslocamento, metonímia e metáfora, respectivamente, a fim de manter os significantes que devem permanecer ocultos. Se enfatizarmos, como quer Rodrigué, a "trama natural" do sonho, criticado por Masotta, iríamos em direção às imagens e à "historinha" do sonho desconsiderando seus significantes. Por fim, a significação não é, de modo algum, legível no interior de um processo global do signo e do símbolo, mas das articulações da cadeia significante em um a posteriori.

Apontamos com a teoria freudiana como está equivocada a ideia de tratar o sonho como uma fenomenologia da totalidade que a interpretação se empenharia em substituir por um símbolo, com outro conteúdo, porém inteligível. Para Freud/Lacan o método adequado seria o do deciframento. O sonho deve ser escutado, lido, como texto cifrado, como pudemos ler nas palavras de Freud. Cada elemento pode ser traduzido. É importante apontar esse caráter fragmentário da interpretação nos sonhos, porque ele faz parte da própria lógica da interpretação. Cada fragmento possibilita infinitas 
interpretações pelo aspecto da sobredeterminação. Mas há um limite para a interpretação como nos indica Freud. Com relação aos sonhos, observa que eles têm um núcleo irredutível que ele denomina "umbigo do sonho", ao qual não se tem acesso. Este ponto é referido na estrutura do inconsciente como "ponto cego", pela sua impossibilidade de inscrição pelo Simbólico, e implica o encontro com o Real, como observará mais tarde Lacan.

No caso do sonho de Anna Freud, a tradução para as línguas estudadas não invalidou, como pudemos constatar, os argumentos apresentados por Masotta. É a estrutura da linguagem e o inconsciente estruturado como uma linguagem, além das elaborações freudianas e lacanianas, que estão em questão para a interpretação do sonho. Não há problema algum em falar nas semelhanças formais e sonoras, suas diferenças, na repetição do grupo fônico, no ordenamento retórico, na hierarquia interna e autônoma das palavras e das frases e a restituição do sentido pelo "denominador comum" indicando a importância dos parênteses. A pequena Anna habita a língua e seu desejo aparece articulado ("realizado") pelas palavras já existentes no código da língua, nas paronomásias, ${ }^{4}$ e nas escansões. Além disso, como bem observa Masotta, "os psicanalistas podem até escamotear o significante mas os tradutores não.” (1971, p. 61). Isso é o que acontece: o sujeito Anna toma posse das guloseimas enumerando as delícias que gostaria de ter comido. Nas línguas analisadas, a tradução reproduz bastante bem o texto em alemão e permite verificar a questão do significante no sonho.

"Anna Fweud, stwawbewwies, wild stwawbewwies, omblet, pudden!" (Freud, 1998, p. 163, Trad. James Stratchey).

"Ana F(r)eud, f(r)esas, f(r)ambuesas, bollos, papilla" (Freud, 1968, p. 322, Trad. Lopez Ballesteros).

“Anna F. eud, Er(d)beer, Hochbeer, Eier(s)peis, Papp” e “Anna F., fesas, fesas silvestes, evos, papia” (Freud, 1976, p. 149, Trad. José Luiz Etcheverry)

“Anna, grosses fraises, framboises, flans, bouillies"(Lacan, 1981, p. 259)

“Anna F. eud, Er(d)beer, Hochbeer, Eier(s)peis, Papp”(Freud, 1972, p. 134)

Há de fato, como diz Masotta, uma repetição de um grupo fônico na escansão que a repetição introduz, Erdbeere e Hochbeer, um ordenamento retórico e uma hierarquização interna e autônoma das palavras e das frases, na atomização do significado da frase e na restituição do sentido introduzido pela mesma repetição. Um “denominador comum", como destaca Lacan (1956, p. 259), apontado pela importância dos parênteses, que indicam as letras não pronunciadas por Anna Freud. Embora sonhe em alemão, a observação "genial" de Rodrigué acaba por ratificar a crítica mais 
contundente, na época, de seu colega Masotta: não se leem e nem se estudam mais os textos de Freud, não se trata de uma questão de tradução.

"Quando um trabalho de interpretação fica concluído, percebemos que um sonho é a realização de um desejo" (Freud, 1972, p.130). Na psicanálise, o sujeito está implicado no sentido, e ele escreve nas palavras que enuncia, como vimos, a singularidade de seu desejo (Frota, 2000, p. 42).

\section{Notas}

${ }^{1}$ MASOTTA, O. Introdução à leitura de Lacan. Campinas: Papirus Editora, 1988, p. 133.

2 “o contrário do postulado por Freud.". Ibidem, p. 137.

${ }^{3}$ Jogo de palavras de Lacan com a expressão pas de sens, sem sentido, não-senso, em francês, utilizando também outro possível significado, a partir da homofonia, da expressão, como passo de sentido.

4 "Figura de linguagem que extrai expressividade da combinação de palavras que apresentam semelhança fônica (e/ou mórfica), mas possuem sentidos diferentes (p.ex.: anda possuído não só por um sonho, mas pela sanha de viajar)"; (Houaiss, 2001, p. 2137).

\section{Referências bibliográficas}

ASSOUN, P-L. "Le rêve d'enfance". In: ASSOUN, La lettre de l'enfance et de l'adolescence. Eres, 2008, $\mathrm{n}^{\circ}$ 71, pp. 13-24.

FREUD, S. "La interpretación de los sueños”. In: FREUD, Obras Completas. Madrid: Biblioteca Nueva, trad: López-Ballesteros, 1968, vol. 2, p. 322.

FREUD, S. "Die Traumdeutung”. In: FREUD, Gesammelte Werke, 1972c, vol. II/III.

FREUD, S. "Interesse da psicanálise para as ciências não psicológicas." In: FREUD, Obras Completas. Local, Imago, vol. XIII, 1969, pp. 211-226.

FREUD, S. "Interpretação dos sonhos". In: FREUD, Obras Completas. Rio de Janeiro: Imago Editora Ltda, 1969, vol. IV, p. 139.

FREUD, S. "Das Interesse an der Psychoanalyse". In: FREUD, Gesammelte Werke, 1972, vol. VIII, p. 389.

FREUD, S. "Die Traumdeutung". In: FREUD, Freud-Studienausgabe, Band IV, Frankfurt, S. Fischer Verlag, 1972b, p. 229.

FREUD, S. The Interpretation of Dreams. New York: Avon Books, Trad: James Stratchey, 1998, p. 163.

FREUD, S. "Cinco lições de psicanálise". In: FREUD, Obras Completas. Rio de Janeiro: Imago Editora Ltda, 1969, vol. XI, pp. 3-46.

FREUD, S. "La interpretación de los sueños". In: FREUD, Obras Completas. Buenos Aires: Amorrortu, Trad. José Luiz Etcheverry, 1976, vol. IV, p. 149. 
FROTA, M.P. A singularidade na escrita tradutora. Rio de Janeiro: Pontes Editora, 2000.

KOOP, G. (Org.) El psicoanálisis y las teorías del lenguaje. Buenos Aires: Ciudad de la editorial, 1988.

LACAN, J. Le séminaire, livre III, Les Psychoses. Paris : Éditions du Seuil, 1981.

LACAN, J. Seminário, livro 3, As psicoses. Rio de Janeiro: Jorge Zahar Editor, 1985.

LACAN, J. "A instância da letra no inconsciente". In: LACAN, Escritos. Rio de Janeiro, Jorge Zahar Editor, 1998, pp. 496-533.

LACAN, J. "Problemas Cruciais para a psicanálise". In: FREUD, Outros escritos. Rio de Janeiro, Jorge Zahar Editor, 2003, pp. 206-209.

MASOTTA, O. "Leer a Freud". Revista Argentina de Psicología, Ano 1, n 1, 1969, pp. 19-25.

MASOTTA, O. "Anotaciones para un psicoanálisis de E. Rodrigué". Cuadernos Sigmund Freud, nº 1. Buenos Aires: Nueva Visión, 1971, pp. 60-75.

MASOTTA, O. Introdução à leitura de Lacan. Campinas: Papirus Editora, 1988.

MILNER, J-C. O amor da língua. Porto Alegre: Editora Artes Médicas, 1987.

RODRIGUÉ, E. "Leer a Rodrigué". Revista Argentina de Psicología. Ano 1, no 2 , dezembro de 1969, p. 127. 